\title{
GESTÃO DE CUSTOS NAS INDÚSTRIAS FILIADAS À ASSOCIAÇÃO COMERCIAL, INDUSTRIAL E AGRÍCOLA DE UMUARAMA - ACIU: NÍVEL DE INTENSIDADE NO USO DE INFORMAÇÕES DE CUSTOS NO PROCESSO DECISÓRIO
}

Gervaldo Rodrigues Campos ${ }^{1}$

CAMPOS, G. R. Gestão de custos nas indústrias filiadas à Associação Comercial, Industrial e Agrícola de Umuarama - ACIU: nível de intensidade no uso de informações de custos no processo decisório. Rev. Ciênc. Empres. UNIPAR, Umuarama, v. 20, n. 2, p. 241-254, jul./dez. 2019.

RESUMO: Este trabalho teve como objetivo verificar como está atualmente estruturado o sistema de custos das indústrias filiadas à Associação Comercial, Industrial e Agrícola de Umuarama - ACIU, bem como identificar o nível de intensidade no uso das informações de custos no processo decisório por essas organizações empresariais, sobretudo no tocante à formação do preço de venda. Para tanto, realizou-se uma pesquisa de campo por intermédio da aplicação de questionário com questões fechadas, encaminhado por e-mail. Com base nos resultados atingidos, foi possível concluir que a maioria absoluta das empresas participantes da pesquisa utiliza planilha ou software para determinar e controlar os custos envolvidos na sua atividade. Das 59 empresas participantes da pesquisa, 48 (81,36\%) assim afirmaram.A maioria afirmou também fazer uso de ferramenta gerencial de gestão de custos por intermédio do sistema de custos implantado, pois $38(64,41 \%)$ fizeram tal afirmação. Por outro lado, o trabalho constatou ainda que a maioria das organizações pesquisadas possuem sistemas de custos claramente identificados. Dentre as decisões que são tomadas no contexto do processo decisório com base nos sistemas de custos utilizados, das 59 empresas participantes da pesquisa, 36 afirmaram que decidem a formação do preço de venda dos seus produtos; 14 afirmaram decidir sobre a margem de lucro dos seus produtos e 9 afirmaram decidir sobre compra ou produção dos seus produtos. Conclui-se, com este trabalho, que as indústrias filiadas à Associação Comercial, Industrial e Agrícola de Umuarama - ACIU possuem sistemas de custos claramente estruturados. A pesquisa também revelou a necessidade de melhora na eficiência dos controles dos seus custos de produção, sobretudo no tocante à integração da informação dos custos com as demais áreas da gestão da empresa, fator indispensável para a permanência das organizações neste ambien-

DOI: $10.25110 /$ receu.v20i2.7642

${ }^{1}$ Professor do Curso de Ciências Contábeis da UNIPAR, unidade universitária de Umuarama 
te altamente competitivo.

PALAVRAS CHAVE: Gestão de custos; Sistema de custos; Processo decisório.

\section{COST MANAGEMENT IN INDUSTRIES MEMBERS OF THE BUSINESS, INDUSTRIAL AND AGRICULTURAL ASSOCIATION OF UMUARAMA (ACIU): INTENSITY LEVEL OF COST INFORMATION USE IN DECISION-MAKING PROCESS}

ABSTRACT: The purpose of this work was to verify how the cost system of industries members of the Business, Industrial and Agricultural Association of Umuarama - ACIU is currently structured and to identify the intensity level of using cost information on the decision-making process, especially related to the sale price formation. In order to do so, a field survey was carried out through the application of a closed-end questionnaire sent by e-mail. Based on the obtained results, it was possible to conclude that the absolute majority of the surveyed companies use a spreadsheet or software to define and control the costs involved in their activity. Among the 59 companies that participated in the research, $48(81.36 \%)$ positively answered for the use of spreadsheets. The majority also make use of a cost management tool through the implemented cost system, which was stated by 38 companies (64.41\%). Additionally, the study showed that most of the target organizations have their cost systems clearly identified, and that among the decisions taken by them in the decision-making process based on the cost systems they use, from the 59 companies surveyed, 36 state they decide the formation of the sale price of their products; 14 decide on the profit margin of their products; and 9 decide on the purchase or production of their products. It is possible to conclude that the industries members of the Business, Industrial and Agricultural Association of Umuarama - ACIU have a clearly structured cost system. The research also revealed the need to improve the efficiency of their production cost controls, especially regarding the integration of cost information with other company management areas as an indispensable factor for the permanence of organizations in this highly competitive environment.

KEYWORDS: Cost management; Cost system; Decision-making process.

\section{GESTIÓN DE COSTES EN LAS INDUSTRIAS FILIADAS A LA ASSOCIAÇÃO COMERCIAL, INDUSTRIAL E AGRÍCOLA DE UMUARAMA - ACIU: NIVEL DE INTENSIDAD EN EL USO DE INFORMACIONES DE COSTES EN EL PROCESO DECISORIO}

RESUMEN: Esta investigación tuvo como objetivo verificar cómo está actualmente estructurado el sistema de costes de las industrias afiliadas a la Associação 
Comercial, Industrial e Agrícola de Umuarama - ACIU, así como identificar el nivel de intensidad en el uso de las informaciones de costes en el proceso decisorio por esas organizaciones empresariales, sobre todo en lo que se refiere a la formación del precio de venta. Para ello, se realizó una investigación de campo por intermedio de la aplicación de cuestionario con cuestiones cerradas, encaminado por e-mail. Con base en los resultados alcanzados fue posible concluir que la mayoría absoluta de las empresas participantes de la investigación utiliza planilla o software para determinar y controlar los costos involucrados en su actividad. De las 59 empresas participantes de la encuesta, 48 (81,36\%) lo afirmaron. La mayoría afirmó también hacer uso de herramienta gerencial de gestión de costes por intermedio del sistema de costos implantado, pues $38(64,41 \%)$ hicieron tal afirmación. Por otro lado, la investigación constató que la mayoría de las organizaciones encuestadas tienen sistemas de costes claramente identificados. Entre las decisiones que se toman en el contexto del proceso decisorio con base en los sistemas de costes utilizados, de las 59 empresas participantes en la investigación, 36 afirmaron que deciden la formación del precio de venta de sus productos; 14 afirmaron decidir sobre el margen de beneficio de sus productos y 9 afirmaron decidir sobre la compra o la producción de sus productos. Se concluye, con esta investigación, que las industrias afiliadas a la Associação Comercial, Industrial e Agrícola de Umuarama - ACIU tienen sistemas de costes claramente estructurados. La investigación también reveló la necesidad de mejora en la eficiencia de los controles de sus costos de producción, sobre todo en lo que se refiere a la integración de la información de los costos con las demás áreas de gestión de la empresa, factor indispensable para la permanencia de las organizaciones en este ambiente altamente competitivo.

PALABRAS CLAVE: Gestión de costes; Sistema de costes; Proceso decisorio.

\section{INTRODUÇÃO}

O mercado atual em que as empresas se encontram inseridas está altamente competitivo, isto é, a concorrência nunca antes esteve tão acirrada. São muitos os desafios a serem superados pelos gestores apenas no campo da concorrência, principalmente em razão da diversidade de empresas disputando o mesmo mercado, sobretudo pela da facilidade hoje em dia de se empreender em qualquer lugar do mundo. Assim, as empresas nacionais sofrem concorrência de empresas de outros países.

Por outro lado, as empresas brasileiras ainda têm de enfrentar diversos outros desafios locais que, muitas vezes, as colocam em grande desvantagem frente à concorrência internacional, tais como: recursos escassos e com juros altos, mão de obra pouco qualificada, baixo nível tecnológico e de automação, 
baixíssimo crescimento econômico, etc. Isto quando não há retração econômica, altos custos logísticos em razão dos modais utilizados e principalmente o alto custo tributário, que é um dos maiores do mundo e, o que é pior, a maior parte da carga tributária brasileira está centrada nos tributos indiretos, os quais possuem impacto direto nos custos de produção.

Diante desse cenário perverso que permeia a vida das organizações empresariais no Brasil, a busca pela sobrevivência passa inevitavelmente pela eficiência na produção, na comercialização, na gestão e acima de tudo nos controles, em especial nos controles dos custos de produção. Somente a contabilidade de custos bem estruturada possibilita tais controles ao gestor.

A contabilidade de custos, que surgiu inicialmente como meio para se avaliar os estoques das indústrias no final do século XVIII, evoluiu e hoje desempenha duas importantes funções, auxílio ao controle e tomada de decisões nas organizações.

Segundo Martins (2010), no que diz respeito ao controle, a missão mais importante da contabilidade de custos é fornecer dados para o estabelecimento de padrões, orçamentos e outras formas de previsão, para depois comparar com o efetivamente acontecido.

Já no tocante à tomada de decisões, o seu papel consiste em produzir informações relevantes com consequências não somente no curto, mas também no longo prazo, como, por exemplo, lançamento de novos produtos, corte de produtos, decisão sobre produzir ou comprar, terceirizar ou não, gestão de preços de venda etc.

A gestão de custos se apresenta como uma das principais ferramentas de planejamento, análise e controle das atividades operacionais das empresas, visando à maximização dos resultados econômico-financeiros. Para isso, as organizações devem conhecer seus custos e despesas operacionais, estruturando seu modelo de formação de preços, tomando decisões mais acertadas, estabelecendo estratégias de segmentação de mercado e, finalmente, gerando lucro.

Os custos tornam-se altamente relevantes quando da tomada de decisões em uma organização. Devido à alta competição, as empresas já não podem mais definir seus preços de acordo com os custos incorridos, e sim, com base nos preços praticados no mercado em que atuam (FRANCO, 1996).

Para isso, faz-se necessário que a ferramenta "gestão estratégica de custos" seja difundida em maior escala e detalhamento, como também utilizada dentre os empresários e contadores que almejem melhorias substanciais em qualidade, redução de custos e aumento de rentabilidade do seu negócio.

Diante do exposto, este trabalho tem como objetivo verificar como está estruturado atualmente o sistema de custos das indústrias filiadas à Associação Comercial, Industrial e Agrícola de Umuarama - ACIU, bem como identificar o 
nível de intensidade no uso das informações de custos no processo decisório por essas organizações empresariais, sobretudo no tocante à formação do preço de venda.

\section{REVISÃO BIBLIOGRÁFICA}

Conforme Bornia (2010), o mercado atualmente é competitivo, com produtos de baixo preço, boa qualidade, constantes modificações de projetos, vida útil curta e muitos modelos diferentes à escolha do cliente.

Para sobreviver neste mercado, é clara a necessidade cada vez maior de se tomar decisões acertadas e tempestivas, isto é, como produzir mais com menos, mantendo uma qualidade de excelência e ainda se antecipar aos concorrentes, diante dos desejos e expectativas do público consumidor.

Para Santos (2000), o controle dos custos representa o cérebro, o pulmão, o coração ou o espírito, sem o qual uma firma não sobreviveria. Ainda segundo o mesmo autor, qualquer atividade que manipule valores está sujeita ao controle de custos.

Não importa o tamanho do negócio. Independe de ser um microempreendedor individual, micro ou pequena empresa, empresa de médio ou grande porte, todos dependem da eficiência no controle dos custos. O lucro, que consiste na diferença positiva entre a receita do negócio e os seus custos e despesas totais no sentido amplo, representa, na maioria das vezes, uma questão de sobrevivência da empresa.

A correta apuração, a análise e o controle dos custos de produção dos bens e serviços têm sido atualmente uma preocupação cada vez maior dos empresários e dos gestores das organizações. Essa preocupação se justifica pela grande concorrência que se estabeleceu nos últimos anos, devido à abertura de mercado. Grandes empresas de outros países instalaram-se e passaram a concorrer com as empresas nacionais, as quais não possuem o mesmo poder de investimentos em tecnologia que as estrangeiras.

A análise dos custos consiste em indispensável instrumento de avaliação de desempenho e de tomada de decisão, o qual possibilita à administração o alcance dos objetivos definidos, sobretudo em termos de resultados.

Segundo Santos (2000), quando da análise dos custos os seguintes objetivos básicos devem ser levados em conta: custo e ganho marginal por produto; resultado de venda por produto; custo fixo da estrutura instalada; nível mínimo de vendas desejado; entre outros.

Empresas nacionais, nas últimas décadas, vêm tentando obter melhor posicionamento competitivo dentro do mercado e, para isso, procuram se modernizar, conseguindo recursos por meio de linhas de créditos mais acessíveis, mão 
de obra especializada e redução de desperdício de tempo e material nas fases de produção.

As empresas brasileiras enfrentam cenário desfavorável, com desafios de diversas naturezas, como recursos escassos e caros, altos custos logísticos, mão de obra cara e de baixa produtividade, burocracia que impede a produção e, acima de tudo, a alta carga tributária. A sobrevivência das empresas passa necessariamente por eficiência na gestão dos custos, que somente um sistema bem desenhado para o negócio pode proporcionar.

Além de informar sobre os custos de produtos e serviços, o sistema de custos deve também oferecer informações sobre os gastos ocorridos nos diversos departamentos que compõem a estrutura organizacional da empresa, possibilitando detectar qual área ou departamento está sendo responsável pelo aumento dos gastos, facilitando o controle gerencial e a elaboração de orçamentos.

O mercado no mundo atual tornou-se muito instável, se comparado com o de há poucos anos, modificando-se numa velocidade jamais imaginável. Esta realidade exige dos gestores novas habilidades no gerenciamento das empresas, adequando seus instrumentos de gestão às necessidades do momento.

Segundo Martins (2010), com o significativo aumento de competitividade que vem ocorrendo na maioria dos mercados, seja industrial, comercial ou de serviços, os custos tornam-se altamente relevantes quando da tomada de decisões em uma empresa.

Este aumento da concorrência tem provocado profundas modificações nos sistemas produtivos das empresas. A tendência dessas modificações pode ser percebida comparando o sistema produtivo da empresa atual com a empresa de alguns anos atrás.

No passado, a grande maioria da fabricação acontecia no sistema de produção em série, isto é, se produzia em grandes lotes padronizados. Não havia diversificação de produtos. A vida útil dos produtos era longa. As empresas usavam estoques elevados, tanto de produtos acabados, produtos em fabricação ou de matéria-prima. Naquele período, o nível de utilização da capacidade da fábrica era geralmente de $100 \%$, na medida em que as capacidades instaladas eram inferiores à demanda de mercado.

Como havia poucas empresas dominando determinados segmentos de mercado, os preços praticados por elas podiam ser altos, porque o mercado suportava. As empresas não se preocupavam com o aprimoramento contínuo da eficiência, pois o mercado, menos competitivo, absorvia as ineficiências, tanto na produção quanto na gestão.

$\mathrm{Na}$ empresa atual há uma necessidade de flexibilidade na produção, ou seja, fabricam-se produtos com diversos modelos, feitos em prazos mais curtos, com menor vida útil e prazo reduzido de entrega ao cliente. A produção deve ser 
efetuada em lotes pequenos, com alta qualidade. Neste cenário, se faz necessário, por parte das empresas, um controle eficiente dos custos de produção e a constante melhoria dos processos produtivos, como condição indispensável para se manterem vivas neste mercado altamente competitivo.

O controle efetivo das atividades produtivas é condição indispensável para que qualquer empresa possa competir em igualdade de condições com seus concorrentes. Sem a capacidade de avaliar o desempenho de suas atividades e de intervir rapidamente para a correção e melhoria dos processos, a empresa estará em desvantagem frente à competição mais eficiente (BORNIA, 2010).

A plenitude do controle só é alcançada quando se efetuam ações para a correção de causas de problemas. Não adianta obter as variações e procurar os motivos que as ocasionaram, caso nada seja feito no sentido de se corrigirem situações indesejadas. Assim, a mera utilização de um sistema de custos voltado para o auxílio ao controle, da mesma forma que ocorre com qualquer outro sistema, não garante por si só a obtenção do controle dos processos. Contudo, propicia importante ajuda na obtenção dos padrões e na mensuração do realmente ocorrido, além de facilitar a análise das variações (BORNIA, 2002)

O auxílio à tomada de decisões é outro objetivo, quando as informações geradas pelo sistema de custos são usadas para dar subsídios ao processo de decisão da empresa. As mesmas informações que auxiliam o controle podem propiciar importante ajuda no processo de planejamento da empresa. As informações de custos são de muita importância quando é necessário decidir sobre a terceirização de um item, corte de um determinado produto, compra de novos equipamentos, entre outros.

Em virtude do atual dinamismo da economia, os administradores necessitam de informações confiáveis e rápidas, que lhe possibilitem a tomada de decisões para o alcance e a superação de metas de resultados. Não obstante, um eficiente sistema de gestão de custos de produção consiste em importante ferramenta de auxílio nos processos de tomadas de decisões no contexto das organizações, isto é, pode apoiar várias decisões no cotidiano das empresas, como fixação de preços de venda, decisão de fabricar ou comprar, decisão de terceirizar ou não determinado processo, determinação da lucratividade dos produtos ou serviços, a seleção de mix de produtos etc.

As empresas, em geral, enfrentam dificuldades também no momento da formação dos preços de seus produtos e serviços. Se cometerem erros nessa etapa, podem ocorrer prejuízos e também perda de mercado, visto que o preço sofre grande influência no mercado, em função de levar em conta o poder aquisitivo dos clientes, a qualidade, a oferta, entre outros. De acordo com Bruni (2010), a formação de preços representa uma das mais importantes e nobres atividades empresariais. A definição equivocada do preço pode arruinar um negócio. 
Santos (1999, p. 174) comenta:

A formação de preços deve ser capaz de considerar a qualidade do produto em relação às necessidades do consumidor, a existência de produtos substitutos a preços mais competitivos, a demanda esperada do produto, o mercado de atuação do produto, o controle de preços impostos pelo governo, os níveis de produção e vendas.

Sendo assim, o mercado requer que as empresas ofereçam produtos e serviços de qualidade, mas com preços que o consumidor esteja disposto a pagar. E para isso os preços devem ser suficientes para cobrir todas as despesas e custos, e ainda conter margem suficiente para o retorno sobre o capital aplicado e, principalmente, o lucro desejado pelo investidor.

\section{METODOLOGIA}

Este trabalho foi desenvolvido junto às indústrias filiadas à Associação Comercial, Industrial e Agrícola de Umuarama - ACIU e procurou atingir os seguintes objetivos: verificar como está atualmente estruturado o sistema de custos das indústrias a ela filiadas, bem como identificar o nível de intensidade no uso das informações de custos no processo decisório por essas organizações empresariais, sobretudo no tocante à formação do preço de venda.

Para tanto, estudaram-se as referidas empresas, mediante a aplicação de um questionário estruturado, com questões fechadas.

A metodologia utilizada para a realização da presente pesquisa caracteriza-se como estudo empírico-analítico, realizado por meio de coleta, observação e análise de dados.

Dessa forma, buscando atingir o objetivo proposto, que consiste em identificar a prática utilizada na gestão dos custos da qualidade pelas empresas objeto de estudo deste trabalho, esta pesquisa se caracteriza como descritiva.

Quanto aos procedimentos, Gil $(1999$, p. 65) ressalta que “[...] o elemento mais importante para a identificação de um delineamento é o procedimento adotado para a coleta de dados". Assim, de acordo com o objetivo proposto, utilizar-se-á a pesquisa de levantamento ou survey, pois, ainda segundo o autor, caracteriza-se pela interrogação direta das pessoas cujo comportamento se deseja conhecer e, em seguida, mediante análise quantitativa, obter as conclusões correspondentes aos dados coletados.

Dessa forma, quanto aos procedimentos, caracteriza-se como pesquisa de campo, pois, mediante o envio de um questionário estruturado com questões 
fechadas, buscou-se conhecer o perfil das indústrias filiadas à Associação Comercial, Industrial e Agrícola de Umuarama - ACIU, no tocante à prática de gestão dos seus custos de produção. Para tanto, as empresas objeto desta pesquisa responderam um questionário, encaminhado por e-mail, com questões relativas aos sistemas de custos que utilizam.

A amostra do presente trabalho está representada por 59 (cinquenta e nove) indústrias. Dos 122 (cento e vinte e dois) questionários que foram encaminhados, retornaram 59 (cinquenta e nove) devidamente respondidos, representando, portanto, $48,36 \%$ (quarenta e oito vírgula trinta e seis por cento) das indústrias filiadas à ACIU.

\section{RESULTADOS E DISCUSSÃO}

Neste tópico são apresentadas as análises dos questionários que retornaram respondidos pelas empresas que integram a amostra selecionada por este trabalho.

Com o resultado do trabalho, foi possível definir o perfil dessas organizações, não somente quanto ao porte, mas principalmente quanto ao sistema de controle e gestão dos custos visando à competitividade e quais as principais decisões tomadas com base nas informações produzidas pelos sistemas de custos utilizados por essas organizações.

Quanto ao perfil das empresas que responderam ao questionário no tocante ao número de colaboradores, o trabalho revelou que as indústrias objeto de estudo desta pesquisa, são pequenas empresas. Com relação ao número de funcionários, das empresas que responderam à pesquisa, 39 (trinta e nove) empregam até 50 funcionários; 10 (dez) empregam entre 51 e 100; 4 empregam entre 101 e 500 e 6 empregam mais de 500. Portanto, Umuarama e região conta com pequenas indústrias, isto é, $83 \%$ (oitenta e três por cento) das empresas que responderam à pesquisa são de pequeno porte quando analisadas sob o aspecto do número de funcionários que empregam. Porém, também há médias e grandes empresas instaladas.

De acordo com o Sebrae, empresas com até 99 (noventa e nove) funcionários são classificadas como pequenas empresas e as que possuem entre 100 e 499 são médias empresas e acima de 500 (quinhentos) são grandes empresas (SEBRAE, 2017).

Quanto ao faturamento mensal das empresas pesquisadas, o resultado revelou que a maioria das organizações da amostra fatura até $\mathrm{R} \$ 100.000,00$ (cem mil reais) por mês. Das empresas que responderam o questionário, 28 (vinte e oito) faturam até $\mathrm{R} \$ 100.000,00$ (cem mil reais) por mês; 16 (dezesseis) afirmaram faturar entre $\mathrm{R} \$ 101.000,00$ e $\mathrm{R} \$ 500.000,00$ (cento e um e quinhentos mil 
reais) por mês; 8 (oito) afirmaram faturar entre $\mathrm{R} \$ 501.000,00$ e $\mathrm{R} \$ 1.000 .000,00$ (quinhentos e um e um milhão de reais) por mês e 07 (sete) afirmaram faturar mais de $\mathrm{R} \$ 1.000 .000,00$ (um milhão de reais) por mês.

Conforme estabelece o artigo $3^{\circ}$, inciso II, da Lei Complementar Federal $\mathrm{n}^{\circ}$ 123, de 14 de dezembro 2006, lei que disciplina o Simples Nacional, classificam-se como de pequeno porte as empresas com faturamento anual de até $\mathrm{R} \$ 3.600 .000,00$ (três milhões e seiscentos mil reais); o que equivale a um faturamento mensal de no máximo $\mathrm{R} \$ 300.000,00$ (trezentos mil reais).

Portanto, este trabalho revela mais uma vez que a maioria das indústrias filiadas à ACIU é de pequeno porte também quando classificadas pelo aspecto do faturamento, pois $47,46 \%$ (quarenta e sete vírgula quarenta e seis por cento) da amostra faturam até $\mathrm{R} \$ 100.000,00$ (cem mil reais) reais por mês.

Ainda com relação ao perfil das empresas que fizeram parte do estudo, a pesquisa também identificou o nível de escolaridade do principal dirigente da empresa. O resultado apontou que a maioria possui nível superior: 27 (vinte e sete) empresas são dirigidas por pessoas com nível superior, representando, portanto, $45,76 \%$ (quarenta e cinco vírgula setenta e seis por cento) da amostra.

O estudo também procurou identificar o principal responsável pelo controle dos custos da empresa, bem como pelo controle dos estoques de matérias primas e produtos acabados e o resultado revelou um dado no mínimo curioso, isto é, a pesquisa revelou que tanto o contador terceirizado quanto o dono da empresa são os principais responsáveis por tal atribuição. Porém, quanto ao nível de controle desses itens, a pesquisa revelou que a grande maioria das empresas mantém controle. Das 59 empresas respondentes, 51 afirmaram possuir controle dos estoques de matéria prima e produtos acabados, representando mais de $86 \%$ (oitenta e seis por cento).

Por outro lado, a pesquisa também procurou medir o nível de conhecimento do principal dirigente da empresa quanto ao valor da hora trabalhada dos colaboradores da produção, valor dos estoques de matéria prima e produtos acabados, bem como demais custos de produção, como energia elétrica, aluguel, combustíveis, manutenção e o resultado foi muito interessante sob o ponto de vista da importância do controle. A maioria absoluta afirmou possuir tal conhecimento, com mais de $90 \%$ (noventa por cento) das empresas participantes da pesquisa fazendo tal afirmação.

Quanto à atitude da empresa quando os itens de custos dos seus produtos sofrem aumentos, a pesquisa revelou também um resultado curioso, pois houve uma divisão interessante de opiniões. Ficou dividido quase que de maneira uniforme entre: repassa parcialmente ao preço dos seus produtos; segue a política dos concorrentes; repassa integralmente ao preço dos produtos. Das 59 empresas pesquisadas, 16 afirmaram que repassam parcialmente ao preço dos 
seus produtos; 16 afirmaram que seguem a política dos concorrentes; 17 afirmaram que repassam integralmente ao preço dos seus produtos; o restante (10) mantém inalterado o preço.

O trabalho apontou também que a maioria absoluta das empresas participantes da pesquisa utiliza planilha ou software para determinar e controlar os custos envolvidos na sua atividade, isto é, das 59 empresas, 48 (81,36\% - oitenta e um vírgula trinta e seis por cento) afirmaram fazer uso de planilha ou software para gerenciar os seus custos de produção. A maioria (38 empresas, ou $64,41 \%$ - sessenta e quatro vírgula quarenta e um por cento da amostra) afirmou também fazer uso de ferramenta gerencial de gestão de custos por intermédio do sistema de custos implantado.

Quanto aos principais benefícios da utilização de ferramenta gerencial de controle de custos, o trabalho destacou como principais benefícios apontados pelas empresas participantes da pesquisa: melhor controle dos custos; maior eficiência na formação do preço de venda dos produtos; auxílio no gerenciamento; dentre outros.

Quanto ao sistema de custeio utilizado para determinação dos custos dos produtos fabricados pelas empresas participantes do trabalho, a pesquisa revelou que a maioria utiliza o custeio por absorção: 35 (trinta e cinco) afirmaram que utilizam o custeio por absorção para apuração dos custos dos produtos que fabricam; 15 (quinze) afirmaram utilizar o custeio direto ou variável; o restante (9) afirmou utilizar outros métodos de custeio. Portanto 59,32\% (cinquenta e nove vírgula trinta e dois por cento) das empresas que responderam o questionário afirmaram utilizar o custeio por absorção para apuração dos seus custos de produção.

Quanto à principal informação de apoio ao processo decisório produzida pelo sistema de custos utilizado pela empresa, o resultado da pesquisa revelou ser o custo unitário do produto, pois 34 das 59 empresas fizeram tal afirmação, representando $57,63 \%$ (cinquenta e sete vírgula sessenta e três por cento) da amostra.

Quanto à principal decisão tomada com base nas informações produzidas pelo sistema de custos utilizado pela empresa, 36 (trinta e seis) afirmaram que decidem a formação do preço de venda dos seus produtos; 14 (quatorze) afirmaram decidir sobre a margem de lucro dos seus produtos; 9 (nove) afirmaram decidir sobre compra ou produção dos seus produtos.

Esse resultado confirma uma tendência muito forte por parte das indústrias por utilizar o método do custeio por absorção para determinação dos seus custos de produção. Porém, o método do custeio direto ou variável, no contexto da gestão dos custos de produção e da geração de informações para apoiar o processo decisório, é o mais indicado. Além de tratar os custos fixos da empresa 
como despesas do período, o que resulta na apuração de um resultado mais confiável na demonstração do resultado do exercício, esse método possibilita também o uso do conceito da margem de contribuição dos produtos, o que consiste em interessante instrumento de gestão e de controle, não somente dos custos, mas do negócio como um todo.

O conceito de margem de contribuição dos produtos é interessante e possui significativa utilidade no contexto do apoio ao processo decisório nas organizações, porque consiste num resultado confiável, isto é, um conceito que não depende de variáveis como volume de utilização da capacidade instalada e forma de rateio dos custos indiretos, como acontece no custeio por absorção.

Conforme Martins (2010), do ponto de vista decisorial, o custeio variável tem condições de propiciar, muito mais rapidamente, informações vitais à empresa. $\mathrm{O}$ mesmo autor afirma ainda que o resultado medido dentro do seu critério parece ser mais informativo à administração.

Quando o consagrado autor Eliseu Martins define que o resultado medido pelo custeio variável parece ser mais informativo à administração, ele está se referindo exatamente às principais características do método, que é esse tratamento dos custos fixos como despesas do período e a possibilidade do uso do conceito de margem de contribuição dos produtos dentro da estrutura do método em questão.

Dentre as vantagens do custeio direto citadas por Padoveze (2004), destaca-se a de que ele é mais fácil para os gerentes entenderem o custeamento dos produtos, pois os dados são próximos da fábrica e de sua responsabilidade, possibilitando a correta avaliação de desempenho setorial.

Ficam evidentes as virtudes do custeio direto, no tocante ao apoio a processo decisório, conforme os autores citados.

Por outro lado, quanto aos instrumentos utilizados pelas empresas participantes da pesquisa para viabilizar o controle dos custos de produção, o trabalho constatou que uma pequena minoria utiliza sistema integrado (ERP). Das $59 \mathrm{em}$ presas que responderam ao questionário, 7 delas, representando apenas $11,86 \%$ (onze vírgula oitenta e seis por cento) afirmaram dispor de sistema integrado de gestão para controle dos custos; 48 (quarenta e oito) afirmaram utilizar planilhas eletrônicas (EXCEL); 4 (quatro) afirmaram fazer uso de sistema informatizado, porém não integrado. Este dado revela importante necessidade, por parte dessas empresas, de investir em tecnologia da informação para melhorar a qualidade dos seus controles internos, sobretudo no tocante à gestão dos custos de produção, haja vista que, somente com sistema ERP se torna possível a integração dos sistemas de gestão, automação de controles, padronização, integração de informações financeiras e, principalmente, a redução de erros. 


\section{CONSIDERAÇÕES FINAIS}

Este trabalho teve como objetivo verificar como está atualmente estruturado o sistema de custos das indústrias filiadas à Associação Comercial, Industrial e Agrícola de Umuarama - ACIU, bem como identificar o nível de intensidade no uso das informações de custos no processo decisório por essas organizações empresariais, sobretudo no tocante à formação do preço de venda. Para tanto, realizou-se uma pesquisa de campo, com aplicação de questionário com questões fechadas, encaminhado por e-mail.

Com base nos resultados da pesquisa, considerando as suas limitações, uma amostra de 48,36\% (quarenta e oito vírgula trinta e seis por cento) das empresas, com as quais foram realizados contatos e responderam o instrumento de pesquisa, pode se afirmar que o universo das indústrias filiadas à ACIU é formado na sua maioria por pequenas indústrias. Das 59 organizações que responderam o questionário, 39 empregam até 50 funcionários; 10 empregam entre $51 \mathrm{e}$ 100 funcionários; 4 empregam entre 101 e 500 funcionários e 6 empregam mais de 500 funcionários, sendo que $74,58 \%$ (setenta e quatro vírgula cinquenta e oito por cento) das organizações que responderam à pesquisa faturam menos de R\$ $500.000,00$ (quinhentos mil reais) por mês.

O resultado revela que a maioria dos postos de trabalho nas indústrias de Umuarama e região se encontra em pequenos negócios.

O trabalho apontou também que a maioria absoluta das empresas participantes da pesquisa utiliza planilha ou software para determinar e controlar os custos envolvidos na sua atividade, isto é, das 59 (cinquenta e nove) empresas participantes da pesquisa, 48 (quarenta e oito) empresas $(81,36 \%$ - oitenta e um vírgula trinta e seis por cento) afirmaram fazer uso de planilha ou software para gerenciar os seus custos de produção. A maioria afirmou também fazer uso de ferramenta gerencial de gestão de custos por intermédio do sistema de custos implantado, isto é, 38 (trinta e oito) empresas, representando 64,41\% (sessenta e quatro vírgula quarenta e um por cento) fizeram tal afirmação.

Quanto à estrutura dos sistemas de custos utilizados por essas pequenas e médias empresas, a pesquisa revelou que a maioria das organizações que responderam ao instrumento de pesquisa possuem sistemas de custos claramente identificados e que dentre as decisões que são tomadas no contexto do processo decisório com base nos sistemas de custos utilizados, das 59 (cinquenta e nove) empresas participantes da pesquisa, 36 (trinta e seis) afirmaram que decidem a formação do preço de venda dos seus produtos; 14 (quatorze) afirmaram decidir sobre a margem de lucro dos seus produtos e 9 (nove) afirmaram decidir sobre compra ou produção dos seus produtos.

Esta pesquisa constatou ainda que uma pequena minoria utiliza sistema 
integrado (ERP), isto é, das 59 (cinquenta e nove) empresas que responderam ao questionário, apenas 7 (sete) representando, apenas $11,86 \%$ (onze vírgula oitenta e seis por cento) afirmaram dispor de sistema integrado de gestão para controle dos custos, 48 (quarenta e oito) afirmaram utilizar planilhas eletrônicas (EXCEL) e 4 (quatro) afirmaram fazer uso de sistema informatizado, porém não integrado.

Conclui-se com este trabalho que as indústrias filiadas à Associação Comercial, Industrial e Agrícola de Umuarama - ACIU possuem sistemas de custos claramente estruturados, porém a pesquisa também revelou a necessidade de melhora na eficiência dos controles dos seus custos de produção, sobretudo no tocante à integração da informação dos custos com as demais áreas da gestão da empresa, fator indispensável para a permanência das organizações neste ambiente altamente competitivo em que as empresas se encontram inseridas.

\section{REFERÊNCIAS}

BORNIA, Antônio Cezar. Análise Gerencial de Custos. 3. ed. São Paulo. Atlas, 2010.

BRASIL. Lei Complementar $n^{\circ}$ 123, de 14 de dezembro de 2006. Disponível em: <http://www.planalto.gov.br/ccivil_03/Leis/LCP/Lcp123.htm>. Acesso em: 12 nov. 2017.

BRUNI, Adriano Leal; FAMÁ, Rubens. Gestão de custos e formação de preços: com aplicações na calculadora HP 12 e Excel. 5. ed. São Paulo: Atlas, 2009.

BRUNI, Adriano Leal. A administração de custos, preços e lucros. 4. ed. São Paulo: Atlas, 2010.

FRANCO, Hilário. Contabilidade industrial. 9. ed. São Paulo: Atlas, 1996.

GIL, Antônio Carlos. Métodos e Técnicas de Pesquisa Social. São Paulo: Atlas, 1999.

MARTINS, Eliseu. Contabilidade de Custos. 10. ed. São Paulo: Atlas, 2010.

PADOVEZE, Luís Clóvis. Contabilidade Gerencial: Um enfoque em Sistema de Informação Contábil. São Paulo: Atlas, 2004.

SANTOS, Joel J. Análise de Custos. 3. ed. São Paulo: Atas, 2000.

SEBRAE - Serviço Brasileiro de Apoio às Micro e Pequenas Empresas. Homepage. Disponível em: http://www.sebrae-pr.com.br/. Acesso em: 14 nov. 2017. 